(C) 1987 ISIJ

\title{
連続鋳造用溶融石英質浸漬ノズルの溶損速度＂ 技術報告
}

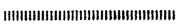

\author{
新谷宏 隆*・川上辰 男*
}

\section{Wear Rate of Fused Silica Submerged Nozzle for Continuous Casting}

\author{
Koryu Aratani and Tatsuo KawaKami
}

\section{Synopsis :}

In order to estimate the wear rate and the campaign life of fused silica submerged nozzle for continuous casting of $\mathrm{Mn}$ steel, investigations were made of used nozzle retrieved from actual continuous casting machine and laboratory corrosion test of fused silica refractories in molten steel with various Mn concentration.

As a result, it was found that the wear rate was proportional to the difference between bulk Mn concentration and equilibrium $\mathrm{Mn}$ concentration, and flow velocity of molten steel through the nozzle.

The wear rate is expressed as follows;

$$
v(\mathrm{~cm} / \mathrm{min})=0.46\left(4.5 \times 10^{-2} U+1.2\right)\left\{13.9\left([\mathrm{Mn}]_{0}-[\mathrm{Mn}]_{e}\right)+1.1\right\} \times 10^{-3}
$$

where $U$ is flow velocity of molten steel through the nozzle $(\mathrm{cm} / \mathrm{min}),[\mathrm{Mn}]_{0}$ is bulk $\mathrm{Mn}$ concentration in steel, and $[\mathrm{Mn}]_{e}$ is equilibrium $\mathrm{Mn}$ concentration for the reduction reaction of $\mathrm{SiO}_{2}$ by $\mathrm{Mn}$ in steel.

Key words; continuous casting; refractory; wear; fused silica; submerged nozzle; Mn steel.

\section{1. 緒}

\section{言}

溶融石英質耐火物のマンガン含有溶鋼による侵食機構 について，筆者らはこれまでに，種々の Mn 濃度をも つ溶鋼中で円柱状の耐火物試験片を回転させ，鋼中の $\mathrm{Mn}$ 濃度や $\mathrm{Si}$ 濃度の経時変化の追跡, 界面の反応生成 物の組成の検討により明らかにしてきた ${ }^{122}$. そ結果 によれば，この侵食反応は鋼中の $\mathrm{Mn}$ による $\mathrm{SiO}_{2}$ (耐火 物)の還元，および還元にともなつて生成した $\mathrm{MnO} に$ よる耐火物の溶解の二つの過程によつて進行し,この侵 食過程は鋼中での Mnの拡散によつて律速されること などが明らかとなつた。

本報ではさらに，その侵食の速度に及ぼす流速の影響 の検討を行うとともに，鋼の連続鋳造に用いられた使用 後の溶融石英質浸漬ノズルを回収してその溶損量を測定 した.これらの結果をもとにして，実機で使用される溶 融石英質浸漬ノズルの溶損速度を算出しその寿命の推定 を行う実験式を提案した。

\section{2. 実 験 方 法}

\section{$2 \cdot 1$ 溶損実耠}

回転法により実験室的な溶損実験を行つた.すなわち, 内径 $50 \mathrm{~mm}$, 高さ $100 \mathrm{~mm}$ のアルミナるつぼに鋼を溶解
し,この中で $20 \phi \times 70 \mathrm{~mm}$ の円柱状耐火物試験片を回 転させ，鋼中の $\mathrm{Mn}$ 濃度の経時変化を測定した．耐火 物試料としては，実機で使用されているものと同じ溶融 石英質浸漬ノズルから直径 $20 \mathrm{~mm}$, 長さ $70 \mathrm{~mm}$ の円柱 状試験片を切り出して用いた。また，マンガン含有溶鋼 は， Mn 濃度が $0.5 \% ， 1 \%$ ，および $2 \%$ となるように 高周波真空溶解炉で溶製したものを用いた．Mn 以外の 成分はすべて一定となるように溶製した，用いた鋼の化 学組成を Table 1 に示した. なお, 後述の実機での実 験で用いた鋼は工程材であり， $\mathrm{Si} ＼textrm{C}$ 等のレベルが異 なるが，その影響については考慮しなかつた。ただ本実 験では，Mn 濃度の影響だけをみるためこの基本組成の 鋼を適宜混ぜ合わせて用いた，実験炉としては，磁製の 炉芯管を内挿した黒鉛抵抗炉を用い，この中に上記のる つぼを設置した。なお，炉内には Ar ガスを流し，中性 雲囲気を保つようにした。実験条件としては，温度

Table 1. Chemical composition of the steels $(w t \%)$.

\begin{tabular}{c|cccccc}
\hline No & C & Si & Mn & P & S & O \\
\hline 1 & 0.011 & 0.49 & 0.50 & 0.003 & 0.006 & 0.0019 \\
2 & 0.013 & 0.49 & 1.00 & 0.003 & 0.006 & 0.0016 \\
3 & 0.014 & 0.50 & 2.01 & 0.003 & 0.007 & 0.0018 \\
\hline
\end{tabular}

昭和 61 年 8 月 4 日受付 (Received Aug. 4, 1986)

* 川崎炉材 (株)技術研究所 (Technical Research Laboratories, Kawasaki Refractories Co., Ltd., Aza-Higashioki Nakahiro Akou 678-02) 
$1550^{\circ} \mathrm{C}$, 試験片の回転速度は 0 から $500 \mathrm{rpm}$ の範囲で 8 水準について行つた.

\section{$2 \cdot 2$ 実機使用後浸漬ノズルの溶損量の測定}

種々の鋳込条件で使用されたあとの溶融石英質ノズル を回収しその溶損量を測定した。ノズルは不均一に溶損 されており，稼動面が 2 3 mm 程度の波状の凹凸をも つため直接的に内径寸法を測定することはできない。そ こで，ここでは溶損された面積を測定し，計算により平 均の溶損寸法を求める方法によつた。なお，断面積の測 定はノズルを長さ方向に 4 等分し，それぞれの切断面を トレーシング紙に写し取つてその面積を測定した。

\section{3. 結果}

\section{$3 \cdot 1$ 溶鋼成分の経時変化}

溶融石英質耐火物とマンガン含有溶鋼との反応にとも なう鋼中の Mn と Si の濃度の経時变化の一例を Fig. 1 に示した。 Mn 濃度は時間とともに減少し，Si 濃度は 増大することがわかる。また，Fig. 2 には試験片の回 転速度を変えた場合の $\mathrm{Mn}$ 濃度の経時変化の一例を示 した。回転速度が速いほど初期の $\mathrm{Mn}$ 濃度の変化速度 が大きい。

\section{$3 \cdot 2$ 実機使用後ノズルの溶損量}

Table 2 に実機の鋳込条件（鋳込量，鋳込時間，鋳込 温度，溶鋼組成）および回収した浸漬ノズルの溶損厚さ

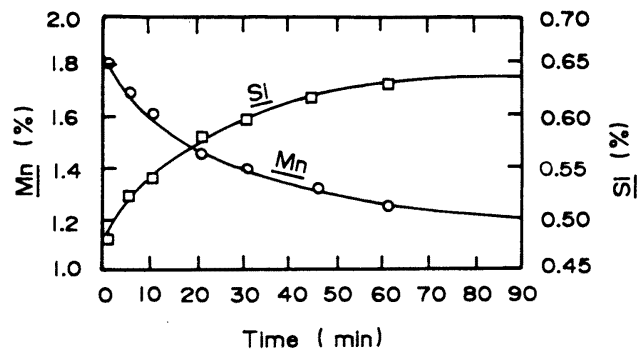

Fig. 1. Change of $\mathrm{Mn}$ and $\mathrm{Si}$ concentration in the steel during the reaction between molten steel with $1.8 \mathrm{wt} \% \mathrm{Mn}$ and fused silica refractories at $1550^{\circ} \mathrm{C}$ and at rotation speed of $300 \mathrm{rpm}$.
を示した。この場合，1本のノズルで多連鋳を行つてい るので鋳込温度および鋼の組成は，各ヒートごとの溶鋼 温度および組成に鋳込量の重みをつけた平均で示した。 また, 鋳込量および鋳込時間は各ヒートの合計で表した。

\section{4. 考}

察

実機における連鋳ノズルの溶損過程は，ノズルの稼動 面が常に新しい溶鋼と接触して侵食が進むという点で, 回転法における溶損過程とは異なる。すなわち，同一 チャージの溶鋼は鋳込みの開始から終了まで同じ成分濃 度をもつており，回転法の場合のように，溶鋼成分の濃 度が侵食反応の進行とともに平衡值に近づくということ がない。したがつて，実機の場合には鋳込みの開始から 終了まで，溶鋼はノズルの侵食に対して常に一定の駆動 力をもつていると考えられる。 そこで，ここでは実機に おける連鋳ノズルの溶損速度を推定するために次のよう な考察を行つた。

まず，鋼中の $\mathrm{Mn}$ 濃度の経時変化を示す曲線（Fig. 1) において，時間 0 の点で接線を引き，その勾配から鋼中 $\mathrm{Mn}$ の濃度変化の初速度 $[\% \mathrm{Mn} / \mathrm{min}]$ を求めた。これ をさらに一般化するため,この濃度に溶鋼の体積と密度 を乗じ，反応界面積で除して溶鋼と耐火物との接触単位 面積当たりの $\mathrm{Mn}$ 重量変化速度 $v_{0}\left[\mathrm{~g} \cdot \mathrm{Mn} / \mathrm{cm}^{2} \cdot \mathrm{min}\right]$ で

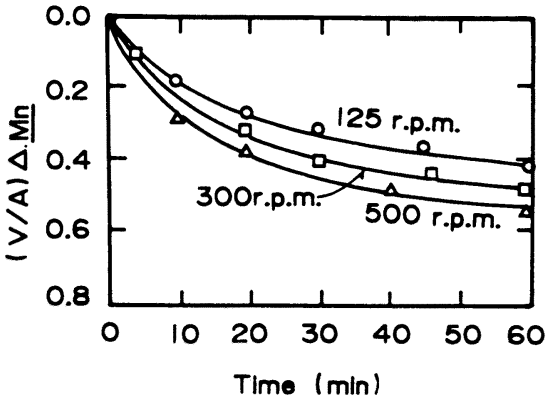

Fig. 2. Effect of rotation speed of the fused silica rods on the change of $\mathrm{Mn}$ concentration in the molten steel during the reaction with the fused silica refractories.

Table 2. Casting conditions of molten steel and eroded thickness of the nozzle.

\begin{tabular}{|c|c|c|c|c|c|c|c|}
\hline \multirow{2}{*}{ No } & \multirow{2}{*}{$\underset{(t)}{\text { Through put }}$} & \multirow{2}{*}{$\underset{(\min )}{\text { Casting time }}$} & \multirow{2}{*}{$\underset{\left({ }^{\circ} \mathrm{C}\right)}{\text { Temperature }}$} & \multicolumn{3}{|c|}{ Chemical composition (wt\%) } & \multirow{2}{*}{$\begin{array}{l}\text { Eroded thickness of the nozzle } \\
(\mathrm{mm})\end{array}$} \\
\hline & & & & Mn & $\mathrm{Si}$ & $\mathrm{C}$ & \\
\hline $\begin{array}{l}1 \\
2 \\
3 \\
4 \\
5 \\
6 \\
7 \\
8 \\
8\end{array}$ & $\begin{array}{l}316.5 \\
559.9 \\
190.0 \\
163.5 \\
411.8 \\
398.8 \\
367.3 \\
454.9\end{array}$ & $\begin{array}{l}156 \\
293 \\
118 \\
102 \\
236 \\
239 \\
239 \\
270\end{array}$ & $\begin{array}{l}1531 \\
1536 \\
1548 \\
1542 \\
1534 \\
1537 \\
1535 \\
1535\end{array}$ & $\begin{array}{l}0.74 \\
0.73 \\
0.94 \\
0.86 \\
0.68 \\
0.71 \\
0.74 \\
0.77\end{array}$ & $\begin{array}{l}0.20 \\
0.20 \\
0.24 \\
0.21 \\
0.19 \\
0.20 \\
0.20 \\
0.21\end{array}$ & $\begin{array}{l}0.18 \\
0.17 \\
0.16 \\
0.15 \\
0.16 \\
0.16 \\
0.16 \\
0.17\end{array}$ & $\begin{array}{l}14.97^{\circ} \\
23.73 \\
16.64 \\
14.08 \\
18.41 \\
21.51 \\
19.12 \\
21.33\end{array}$ \\
\hline
\end{tabular}


表した，溶鋼の温度，流速，組成などが同じであれば， 実機におけるノズルはこれと同じ Mn 量変化速度で侵 食されるものと考えられる.すなわち，実機においては， 大量の溶鋼がノズルを通過するので，回転法実験におけ るような溶鋼と耐火物との反応に伴う鋼の組成の経時変 化はなく, 反応界面における鋼中 $\mathrm{Mn}$ 濃度は常に一定 で，回転法実験における初期 $\mathrm{Mn}$ 濃度での反忘に対す る駆動力 $v_{0}$ と同じ $\mathrm{SiO}_{2}$ 還元能を有すると考えられる.

また，溶鋼中の $\mathrm{Mn}$ 濃度と平衡 $\mathrm{Mn}$ 濃度 $\left(\mathrm{SiO}_{2}\right.$ との 反応により到達すると考えられる平衡濃度）との差が大 きいほど侵食速度は大きくなると予想される，そこで， 回転法で得られた結果をこの方法で整理した。試験片の 回転速度 $300 \mathrm{rpm}$ のデー夕について, 初期 $\mathrm{Mn}$ 濃度 $[\mathrm{Mn}]_{0}$ と平衡 $\mathrm{Mn}$ 濃度（濃度の経時変化曲線の外挿值） $[\mathrm{Mn}]_{e}$ との差 $\left([\mathrm{Mn}]_{0}-[\mathrm{Mn}]_{e}\right)$ と $\mathrm{Mn}$ 重量変化速度 $v_{0}^{\prime}$ との関係を求め Fig. 3 にプロットした。両者の間に は相関関係がみられ，次のような実験式が得られる。

$$
v_{0}{ }^{\prime}=\left\{13.9\left([\mathrm{Mn}]_{0}-[\mathrm{Mn}]_{e}\right)+1.1\right\} \times 10^{-3} \ldots(1)
$$

図において直線が原点を通らない理由は明確ではないが 2,3 の理由が考えられる，その一つは， Mn 濃度の経 時変化の測定は $60 \mathrm{~min}$ までしか行つていないため, 多 くの場合, 外挿値から平衡濃度を求めており, その誤差 が考えられること, 他の理由としては, 鋼中の Mn 濃 度の小さい領域では，後述の侵食反応式，すなわち，鋼 中の $\mathrm{Mn}$ による $\mathrm{SiO}_{2}$ の還元反応（( 5 ) 式）および生成 した（MnO）による酎火物の溶解度応（(6)式）と同

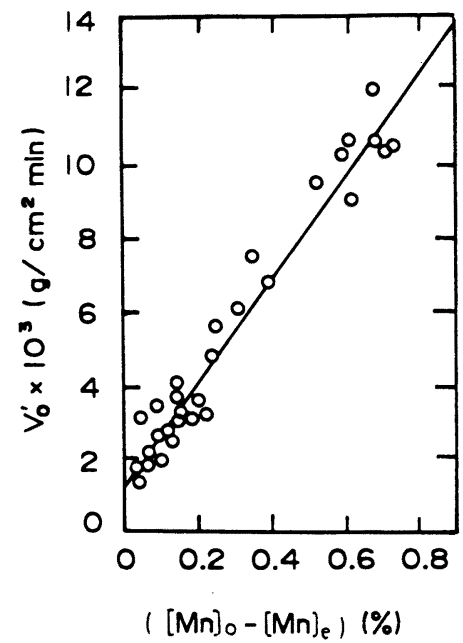

Fig. 3. Relation between the wear rate of fused silica refractories $v_{0}^{\prime}$ and the difference of initial and equilibrium $\mathrm{Mn}$ concentration $\left(\left[\left.\mathrm{Mn}\right|_{0}-[\mathrm{Mn}]_{e}\right)\right.$.
様の反応が溶鉄（Fe）そのものについても起こること などが考えられる。

つぎに，溶鋼の流速の影響を検討するために, Mn 濃 度 $1 \%$ の溶鋼について反応界面での周速と $\mathrm{Mn}$ 重量変 化速度 $v_{0}$ ”との関係を Fig. 4 にプロットした.この図 から，侵食速度に対する流速の影響に関して次の実験式 が得られる.

$$
v_{0}^{\prime \prime}=\left\{4.5 \times 10^{-2} U+1.2\right\} \times 10^{-3}
$$

一般に物質移動律速の反応においては流速が反応速度 に及ぼす影響に関して EISENBERG ら ${ }^{3)}$ ，小坂ら ${ }^{4)}$ ，大井 $ら^{5)}$ の取扱いのように $R e$ 数や $S c$ 数による解析が行わ れる.すなわち，強制対流条件下で固体と流体間の物質 移動に関しては次のような無次元相関が用いられてい $ろ^{4)}$.

$$
k / U=c(R e)^{a-1}(S c)^{b}
$$

鋼の組成や温度等の条件が同一であればその粘度, 密 度その他の物性は同一となるので $(3)$ 式は $k=\alpha U^{a}$ のよ うに簡略化できる． $a$ の值としては，一般に $0.5 \sim 0.8$ の値が報告されている3) 6). 本実験の場合， $a$ の值はこ れらの值より若干大きな値となり，その理由については 今後の検討課題であるが，ここでは，（2)式の関係が初 期 $\mathrm{Mn}$ 濃度 $1 \%$ 以外の溶鋼に対しても同じように成立 すると仮定し，(2)式を $300 \mathrm{rpm}$ のときの $v_{0}{ }^{\prime \prime}$ の值（= 2.6) で除して流速の影響に関する頃とした。これを(1) 式と組み合わせて濃度と流速の両者を含む次のような実 験式を得た。

$$
v_{0}=\left\{\left(4.5 \times 10^{-2} U+1.2\right) / 2.6\right\} \text {. }
$$

$$
\left\{13.9\left([\mathrm{Mn}]_{0}-[\mathrm{Mn}]_{e}\right)+1.1\right\} \times 10^{-3}
$$

一方，マンガン含有溶鋼による溶融石英質耐火物の侵 食反応は既に報告1)2) したように次式で表される.

$\left[\mathrm{SiO}_{2}\right]_{\text {Ref }}+2 \mathrm{Mn}=2(\mathrm{MnO})+\underline{\mathrm{Si}} \cdot$.
$\left[\mathrm{SiO}_{2}\right]_{\text {Ref }}+(\mathrm{MnO})=\left(\mathrm{MnO} \cdot \mathrm{SiO}_{2}\right)$

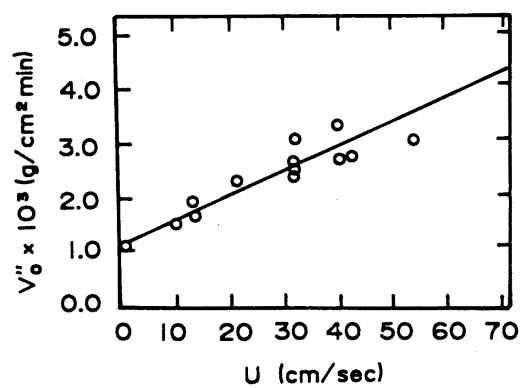

Fig. 4. Relation between the wear rate of fused silica refractories $v_{0}^{\prime \prime}$ and relative flow rate of molten steel $U$. 
（5），（6)式から侵食文応は全体としては

$3\left[\mathrm{SiO}_{2}\right]_{\text {Ref }}+2 \mathrm{Mn}=2\left(\mathrm{MnO} \cdot \mathrm{SiO}_{2}\right)+\underline{\mathrm{Si}}$

この反応式にしたがえば，鋼中の $\mathrm{Mn} の 1 \mathrm{~mol} の$ 減少 に対して $3 / 2 \mathrm{~mol}$ の $\mathrm{SiO}_{2}$ の減少が起こるはずである. したがつて，ノズルの嵩比重 $(=1.90)$ を考慮に入れて, (4) 式の Mn 重量変化速度 $v_{0}$ をノズ溶損速度 $v_{\text {cal }}$ $[\mathrm{cm} / \mathrm{min}]$ に換算し次式を得た。

$$
v_{\text {cal }}=0.33\left(4.5 \times 10^{-2} U+1.2\right)
$$

$$
\left\{13.9\left([\mathrm{Mn}]_{0}-[\mathrm{Mn}]_{e}\right)+1.1\right\} \times 10^{-3}
$$

(8) 式を用いれば, 鋼の $\mathrm{Mn}$ 濃度, 平衡 $\mathrm{Mn}$ 濃度, 流速などからノズルの溶損速度を求めることができる. ここで, Mn 濃度は鋼の分析值または目標組成から，流 速はノズルの内径と鋳片の引抜速度からそれぞれ容易に 得られる。 また, 平衡 $\mathrm{Mn}$ 濃度は次のような方法で推 定することができる。まず（5)式に関して，ELLIOT ら² の熱力学データを用いて次式が得られる.

$\ln \left(a_{\mathrm{Mno}}^{2} \cdot a_{\mathrm{Si}} / a_{\mathrm{SiO}_{2}} \cdot a_{\mathrm{Mn}}^{2}\right)=$

$$
-(2900+7.07 T) / R T \text {. }
$$

反応により生成したマンガンシリケートは既報 ${ }^{1) 2)}$ の データと同じく，本実験の場合も $\mathrm{SiO}_{2}$ で飽和されてお り， $a_{\mathrm{SiO}_{2}}=1$ と考えてよい. また, $\mathrm{FeO}-\mathrm{MnO}-\mathrm{SiO}_{2}$ 系 スラグにおける $\mathrm{MnO}$ の活量については Fig. 5 に示す ように, TURKDOGAN $ら^{8)}$, 藤田ら ${ }^{9)}$, 小島ら ${ }^{10)}$ のデー夕 がある，本実験で侵食実験の後，耐火物試験片の表面に 付着した反応生成物について EPMA によりスポット分 析を行つた結果，反応生成物中の $\mathrm{MnO}$ の含有量は $50 \%$ 前後であつた。したがつて Fig. 5 からその活量は $a_{\mathrm{MnO}}$ $\doteqdot 0.15$ と考えることができる。 また，Si および $\mathrm{Mn} の$ 活量についてはそれぞれ

$$
\begin{aligned}
\log a_{\mathrm{Si}} & =\log f_{\mathrm{Si}}^{\prime}+\log f_{\mathrm{Si}}^{(\mathrm{M} \mathrm{Mn})}+\log [\mathrm{Si}]_{e} \\
& =e_{\mathrm{Si}}^{(\mathrm{Si})}[\mathrm{Si}]_{e}+e_{\mathrm{Si}}^{(\mathrm{Mn})}[\mathrm{Mn}]_{e}+\log [\mathrm{Si}]_{e}
\end{aligned}
$$

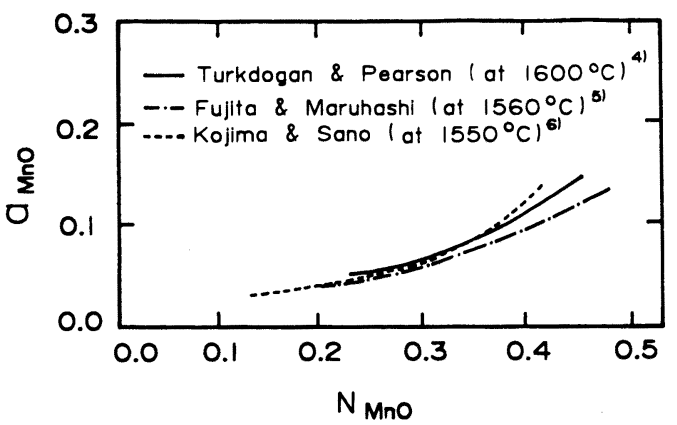

Fig. 5. Relation between the activity of manganese oxide and the mole fraction of $\mathrm{MnO}$ in the $\mathrm{FeO}-\mathrm{MnO}-\mathrm{SiO}_{2}$ slags saturated with silica.
(10)

$\log a_{\mathrm{Mn}}=e_{\mathrm{Mn}}^{(\mathrm{Mn})}[\mathrm{Mn}]_{e}+e_{\mathrm{Mn}}^{(\mathrm{Si})}[\mathrm{Si}]_{e}+\log [\mathrm{Mn}]_{e}$

$$
[\mathrm{Si}]_{e}=[\mathrm{Si}]_{0}+\frac{1}{2}\left([\mathrm{Mn}]_{0}-[\mathrm{Mn}]_{e}\right) M_{\mathrm{Si}} / M_{\mathrm{Mn}}
$$

で与えられる.ここに $e_{\mathrm{A} \mid}^{(\mathrm{B})}$ は相互作用助係数, $M$ は $\mathrm{Si}$ または Mnの原子量である。（9）～(12) 式を用いれば $\mathrm{Mn}$ の平衡濃度 $[\mathrm{Mn}]_{e}$ を求めることができる.

以上の手続きにより熱力学データ ${ }^{11)}$ および使用後の ノズルに関する Table 2 に示した各データから（８)式 を用いてノズルの計算溶損速度 $v_{\text {cal }}$ を求めた。これと 実測の溶損速度 $v_{\text {obs }}$ とを比較して Fig. 6 にプロットし

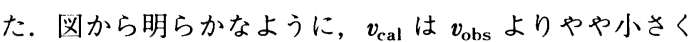
なる傾向を示している．この原因としては，(1)実験を行 つた流速は最高 $50 \mathrm{~cm} / \mathrm{s}$ であるが，実機での流速は最 高 $200 \mathrm{~cm} / \mathrm{s}$ であり，高速側における流速の影響が Fig. 4 の外挿值より大きくなる可能性があること.ただし， EISENBERG $^{3)}$ は安息香酸のグリセリン溶液中への溶解速 度を回転法で検討し, 流速が 8 362 cm/s の範囲で ( 3 ) 式のような無次元式が成立するとしており，この可能性 は比較的小さいものと考えられる. (2)Fig. 3 における 濃度と $\mathrm{Mn}$ 変化速度との関係は, 鋼中の $\mathrm{Si}$ 濃度が $0.5 \%$ のときのプロットであるが，実機の場合はこの濃 度より小さいためその影響があり得ることなどが考えら れる.その他温度の影響などさらに検討を必要とするが, これらの影響を含めて, Fig. 6 の直線の勾配 1.4 を(8) 式に乗じ，実機ノズルの溶損速度 $v$ を次式で推定する ことが叮能である.この式は実験式であり，係数の 1.4

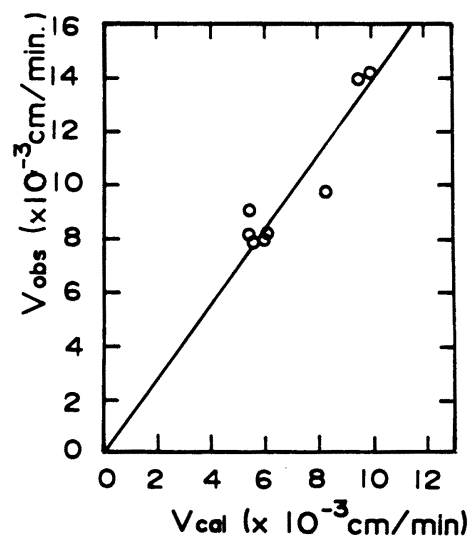

Fig. 6. Plot of observed wear rate of immersion nozzle, $v_{\text {obs }}$, versus calculated wear rate, $v_{\text {cal }}$. 
は本来 1.0 であるべきものであるが, 実験空実験の条 件と実機条件における溶鋼の温度, 流速, 成分濃度等の 相違に起因して大きな值となつたものと考えられる.

$$
v=1.4 v_{\text {cal }}=0.46\left(4.5 \times 10^{-2} U+1.2\right)
$$$$
\left\{13.9\left([\mathrm{Mn}]_{0}-[\mathrm{Mn}]_{e}\right)+1.1\right\} \times 10^{-3}
$$

\section{5. 総括}

鋼の連続鋳造に用いられる溶融石英質浸漬ノズルのマ ンガン含有溶鋼による溶損速度を推定するため, 実機で の使用後のノズルの調查および，回転円简法による実験 室的な侵食実験を実施した。その結果，実機のノズルの 溶損速度は, 鋼中の初期 $\mathrm{Mn}$ 濃度と平衡 $\mathrm{Mn}$ 濃度との 差 $\left([\mathrm{Mn}]_{0}-[\mathrm{Mn}]_{e}\right)$, および溶鋼の流速 $U$ に比例して 大きくなることが明らかとなつた.

侵食実験から得られた溶損速度の推定式と実機から回 収したノズルの実測溶損速度との対比から, 次のような 溶損速度推定式が得られた。

$v(\mathrm{~cm} / \mathrm{min})=0.46\left(4.5 \times 10^{-2} U+1.2\right)$

$$
\left\{13.9\left([\mathrm{Mn}]_{0}-[\mathrm{Mn}]_{e}\right)+1.1\right\} \times 10^{-3}
$$

本実験で調査した回収ノズルの使用条件すなわち，鋼 中の $\mathrm{Mn}$ 濃度が $0.7 \sim 1.0 \%$, 溶鋼温度が $1530^{\circ} \mathrm{C}$ $1550^{\circ} \mathrm{C}$ に近い範囲であれば上式によりノズルの溶損速 度の推定が可能と思われる。

\section{文献}

1) 新谷宏隆, 川上辰男: 鉄と鋼, 72 (1986), p. 1965

2) 新谷宏隆, 川上辰男: 突業協会誌, 94 (1986), p. 1112

3 ) $M$. Eisenberg, $C . W$. Tobias and $C . R$ Wilke: Chem. Eng. Progr. Symp., 51 (1955), p. 1

4 ) 小坂岑雄, 蓑輪 晋: 鉄と鋼, 52 (1966), p. 1748

$5)$ 大井浩, 小口征男, 南参: 鉄と鋼, 56 (1970), p. 991

6 ) 小林弘旺, 尾山竹滋: 窯業協会誌, 82 (1974), p. 546

7 ) J. F. Elliot, $M$. GLEiser and V. Ramakrishna: Thermochemistry for Steelmaking (1963)

8 ) E. T. TURKdogan and J. PEAson: J. Iron and Steel Inst., 175 (1953), p. 393

9 ) 藤田春彦, 丸橋茂昭: 鉄と鋼, 56 (1970), p. 830

10）小島 康，佐野幸吉: 鉄と鋼，51 (1965)， p. 1122

11）大谷正康: 鉄治金熱力学 (1971) [日刊工業新聞社] 